\title{
INFLUÊNCIA DA RELAÇÃO SÓLIDO-LÍQUIDO NA ROTA HIDROMETALÚRGICA DE LIXIVIAÇÃO ÁCIDA DE PLACAS DE CIRCUITO IMPRESSO DE COMPUTADORES PARA RECUPERAÇÃO DE METAIS*
}

\author{
Mariana Alves de Carvalho ${ }^{1}$ \\ Marcos Paulo Kohler Caldas ${ }^{2}$ \\ Jorge Alberto Soares Tenório ${ }^{3}$ \\ Denise Crocce Romano Espinosa ${ }^{4}$
}

\section{Resumo}

O desenvolvimento da indústria e a redução do ciclo de vida de eletroeletrônicos aumentam a geração dos chamados resíduos de equipamentos eletroeletrônicos (REEE). Dentre os REEE, as placas de circuito impresso (PCls) apresentam um teor de metais em sua composição que as torna importante objeto de estudo visando a recuperação destes metais para fins econômicos e, por conseguinte, impede que sejam dispostos no meio ambiente. O presente trabalho tem por objetivos a caracterização de uma amostra de placa mãe de computadores obsoletos e posterior recuperação dos metais via duas rotas hidrometalúrgicas de lixiviação ácida e lixiviação ácida em meio oxidante. A primeira etapa foi realizada com ácido sulfúrico $2 \mathrm{M}$ por 18 horas e a $95^{\circ} \mathrm{C}$; a segunda etapa, de lixiviação em meio oxidante, utilizou também o ácido sulfúrico $2 \mathrm{M}$ como agente lixiviante, e o peróxido de hidrogênio como agente redutor, por 6 horas e a $95^{\circ} \mathrm{C}$. As duas rotas se diferenciaram entre si na proporção sólido-líquido, sendo a primeira de 1:10 e a segunda de 1:20. A rota com proporção 1:20 foi a que apresentou resultado mais positivo, com $100 \%$ de lixiviação de $\mathrm{Ag}, \mathrm{Al}, \mathrm{Cu}, \mathrm{Fe}, \mathrm{Ni}$ e $\mathrm{Zn}$.

Palavras-chave: Reciclagem; Hidrometalurgia; Resíduos de Equipamentos Eletroeletrônicos; REEE.

\section{INFLUENCE OF THE SOLID-LIQUID RATIO ON THE HYDROMETALLURGICAL ROUTE OF ACID LEACHING OF WASTE PRINTED CIRCUIT BOARDS FROM COMPUTER AIMING METAL RECOVERY}

\section{Abstract}

The development of industry and the life cycle reduction of electronics increase the generation of the so-called waste electrical and electronic equipments (WEEE). Among the WEEE, the printed circuit boards (PCBs) have in their composition a high content of metals, what make them an important object of study aiming metal recovery for economic purposes and, therefore, prevent them to be disposed on environment. This work aims the characterization of a sample of a board from obsolete computers and the later the recovery of metals from two different hydrometallurgic routes of acid leaching and acid leaching in an oxidant media. The former was conducted with sulfuric acid $2 \mathrm{M}$ for 18 hours and $95^{\circ} \mathrm{C}$; the latter, in a oxidizing media, also used sulfuric $2 \mathrm{M}$ acid as leaching agente, and hydrogen peroxide as reductor agente, for 6 hours and $95^{\circ} \mathrm{C}$. The difference between the two routes was in the solid-liquid ratio, with 1:10 for the first and 1:20 for the second. The route with 1:20 ratio performed a better result, with $100 \%$ of leaching for the metals: $\mathrm{Ag}, \mathrm{Al}, \mathrm{Cu}, \mathrm{Fe}, \mathrm{Ni}$ e $\mathrm{Zn}$.

Keywords: Recycling; Hydrometallurgy; Waste Electrical and Electronic Equipment; WEEE. 
1 Mestranda em Engenharia Química, Departamento de Engenharia Química, Escola Politécnica, USP, São Paulo, SP, Brasil.

2 Doutor em Engenharia Química, Departamento de Engenharia Química, Escola Politécnica, USP, São Paulo, SP, Brasil.

3 Professor Titular, Departamento de Engenharia Química, Escola Politécnica, USP, São Paulo, SP, Brasil.

4 Professora Associada, Departamento de Engenharia Química, Escola Politécnica, USP, São Paulo, SP, Brasil. 


\section{INTRODUÇÃO}

Tecnologias eletroeletrônicas estão presentes no dia-a-dia do homem em cada vez mais aplicações, o que demanda que estejam em constante desenvolvimento para acompanhar o aumento das necessidades às quais se propõem a contribuir. Tal demanda impulsiona a inovação tecnológica, mas também leva à ocorrência de um ciclo de vida reduzido e elevado índice de obsolescência, tornando a disposição final de eletroeletrônicos um desafio na gestão de resíduos urbanos, com a geração dos chamados REEE (Resíduos de Equipamentos Eletroeletrônicos) [1,2]. Isso porque o aumento da geração de REEE acrescido do fato de que muitas vezes sejam dispostos no meio ambiente sem que haja qualquer tipo de tratamento preliminar, torna-os uma fonte poluidora por possuírem composição complexa, contendo elementos nocivos à saúde humana e ao meio ambiente. Este fato tem crescido em proporção, uma vez que novas tecnologias possibilitaram desenvolver componentes eletrônicos com maior número de camadas de materiais, sendo estes, cada vez mais, de origem heterogênea [3].

Anualmente, estima-se que sejam gerados entre 20 e 50 milhões de toneladas de REEE, com uma fração metálica de cerca $40 \%$ em massa. Trata-se de um volume consideravelmente alto de metais, disposto todos os anos na natureza, o que representa um problema em potencial, ainda mais pelo fato de este número vir crescendo de forma exponencial [2,4]. Por outro lado, os REEE descartados apresentam potencial para a reciclagem, devido à possibilidade de recuperação de metais em sua composição, abrindo uma nova janela de exploração, visto que esses resíduos contêm maior teor de metais do que os minérios dos metais correspondentes, em sua maioria [1,2,5,6].

As placas de circuito impresso (PCls) estão presentes em todos os equipamentos eletroeletrônicos e são compostas de materiais poliméricos, cerâmicos e metálicos, em proporção variada. Normalmente, as frações cerâmica e polimérica variam entre $30-50 \%$ e $20-30 \%$, respectivamente, e 30 a $40 \%$ das PCls é composta de metais $[2,7,8]$. Na fração metálica, é possível encontrar uma ampla gama de metais. Dentre estes metais estão cobre, ferro, alumínio, estanho, zinco, ouro, prata, e metais potencialmente tóxicos como cádmio, mercúrio e cromo, dentre outros em menores quantidades [3,5].

Em 27 de janeiro de 2003, o Parlamento Europeu aprovou a Diretriz Europeia WEEE, relativa aos REEE. Entrando em vigor em 13 de agosto de 2005, seu intuito era reduzir a geração de REEE e definir responsabilidades em seu gerenciamento desde a fabricação até a disposição final, incentivando sua reciclagem [9]. Também em 27 de janeiro de 2003 foi aprovada a Diretriz Europeia RoHS (Restriction on the use of Hazardous Substances), que complementava o caráter da diretriz WEEE e tinha foco voltado à saúde humana e ao meio ambiente. Tal diretriz entrou em vigor a partir de 1 de julho de 2006, e a partir daí, era proibida a circulação no mercado de componentes eletroeletrônicos cujo processo de fabricação fazia uso de substâncias consideradas potencialmente nocivas. Dentre estas substâncias, estão presentes metais como mercúrio, cádmio, cromo hexavalente, e o chumbo, que na forma de liga juntamente com estanho, era o principal componente das soldas das PCls até então $[10,11]$. Como resultado de tais diretrizes, uma nova preocupação a respeito dos REEE, no sentido de ciclo de vida e composição, foi gerada. A partir do momento que ambas diretrizes entraram em vigor e foram difundidas, foi necessário modificar o processo de fabricação das PCls a fim de substituir os componentes proibidos por outros, sem perdas de características e propriedades. Assim, no caso 
da solda cuja composição possuía chumbo, a prata despontou como potencial alternativa e passou a ser utilizada no processo produtivo nas ligas componentes das soldas, inserindo no mercado as chamadas placas lead free.

$\mathrm{O}$ uso de metodologias científicas para reciclagem de PCls objetiva que, ao fim do ciclo de vida, seja possível não só tratar tais resíduos, mas também recuperar os metais ali presentes. Isso torna o estudo acerca da reciclagem de PCls bastante atrativo nos âmbitos sustentável e econômico, uma vez que impede sua disposição na natureza caracterizando um risco de contaminação em potencial - de forma concomitante com o retorno econômico [3].

A reciclagem de REEE visando à recuperação de metais pode utilizar processos físicos, hidrometalúrgicos, pirometalúrgicos e biológicos, todos sendo objeto de estudo para promover melhorias constantes, tornando-os aplicáveis futuramente a escalas maiores. Na prática, sua aplicação em processos reais ainda ocorre em escalas menores ou por métodos convencionais. Tais métodos promovem baixa recuperação de metais, gerando também uma grande quantidade de resíduos, além de negligenciarem o tratamento correto dos mesmos, aumentando a insalubridade do processo e a emissão de compostos poluentes [1].

A recuperação de metais de $\mathrm{PCls}$ utilizando a hidrometalurgia remonta à década de 60 e é baseada na lixiviação dos componentes metálicos da placa, utilizando, na maioria das vezes, substâncias ácidas ou alcalinas sob condições específicas de temperatura, pressão, agitação e concentração. O licor contendo os metais em meio aquoso é submetido a um processo subsequente para recuperação dos metais de interesse [5].

O presente trabalho visa a caracterização de uma placa mãe de computadores obsoletos e a recuperação dos metais nela contidos por meio do processamento hidrometalúrgico.

\section{MATERIAIS E MÉTODOS}

Foram utilizadas PCls oriundas de computadores obsoletos cedidas pelo Centro de Descarte e Reuso de Resíduos de Informática da Universidade de São Paulo (CEDIR/USP). Foi utilizada uma amostra de Placa Mãe lead free. O diagrama de blocos contendo a sequência da metodologia utilizada encontra-se na Figura 1: 


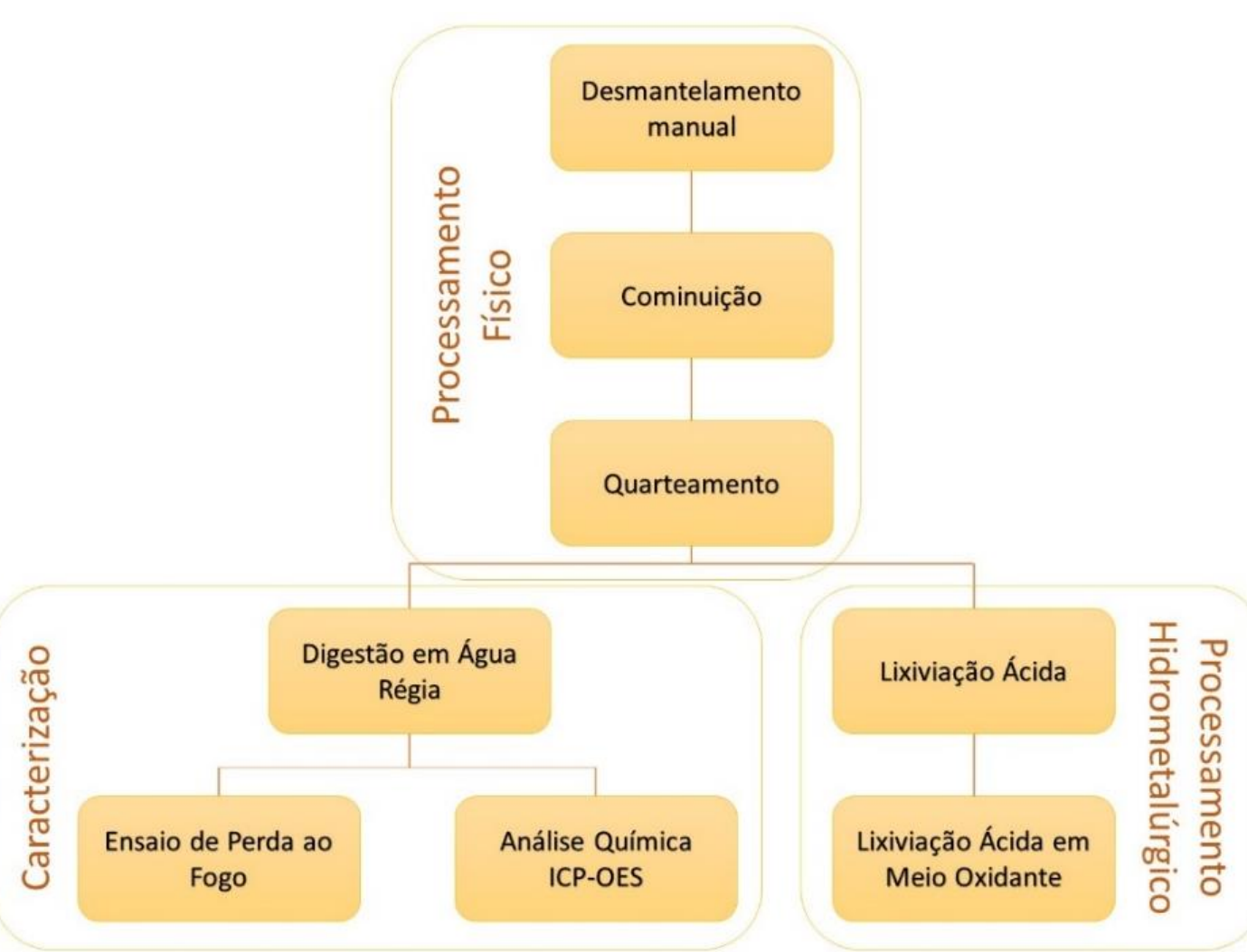

Figura 1. Diagrama de Blocos da metodologia aplicada no presente trabalho

\subsection{Processamento Físico}

A Placa Mãe foi desmantelada manualmente para retirada de peças móveis e de maior tamanho, e seguiu para a etapa de cominuição para liberação do material e aumento da área superficial.

\subsubsection{Cominuição}

$\mathrm{Na}$ etapa de cominuição, as placas passaram por dois moinhos, sendo o primeiro de facas com grelha de $9 \mathrm{~mm}$ modelo RONE FA2305, e o segundo de martelos com grelhas de 2mm modelo MDM 18/18 da marca Astecma.

\subsubsection{Quarteamento}

Após a moagem, a amostra seguiu para o quarteamento para ser dividida, de forma homogênea, em lotes menores de peso $20 \pm 5 \mathrm{~g}$.

\subsection{Caracterização}

A amostra foi, então, caracterizada para determinação das frações de cada tipo de material - polimérico, cerâmico e metálico - constituinte, além da identificação dos metais da amostra. Para isso, foi realizada sua digestão em água régia seguida de filtração, resultando em uma fração sólida e um licor. A fração sólida seguiu para o ensaio de perda ao fogo, e o licor, para análise química. 


\subsubsection{Digestão em água régia}

Uma fração da amostra quarteada com massa de $5 \mathrm{~g}$ foi solubilizada em $100 \mathrm{~mL}$ de água régia, de forma a estabelecer uma proporção solido-líquido de 1:20, em contato direto por 24 horas à temperatura ambiente. Após este tempo, foi realizada a filtração simples da solução em papel de filtro quantitativo de filtragem rápida e porosidade $0,75 \mu \mathrm{m}$. A fração líquida contendo os metais solubilizados seguiu para análise química.

A fração sólida retida no papel de filtro - contendo os materiais cerâmicos e poliméricos - foi lavada com água deionizada e levada à estufa na temperatura de $60 \pm 5^{\circ} \mathrm{C}$ por 24 horas, para seguir para o ensaio de perda ao fogo.

\subsubsection{Ensaio de perda ao fogo}

Após a saída da estufa, a fração sólida foi colocada em uma navícula de porcelana e pesada em balança analítica. A navícula foi então levada a um forno tipo mufla com taxa de aquecimento de $10^{\circ} \mathrm{C} /$ minuto até atingir a temperatura de $800^{\circ} \mathrm{C}$. Esta temperatura foi mantida por 1 hora e o forno desligado para resfriamento da amostra. Após atingir a temperatura ambiente, a amostra foi pesada novamente. $O$ peso final da amostra equivale à massa de material cerâmico que a compõe, e a diferença entre as massas inicial e final equivale à massa de material polimérico.

\subsubsection{Análise Química}

Do licor obtido após a filtração, uma alíquota de $10 \mathrm{~mL}$ foi retirada para análise química com a técnica de espectrometria de emissão óptica com acoplamento de plasma induzido (ICP-OES).

\subsection{Processamento Hidrometalúrgico}

Foram utilizadas duas rotas que se diferenciavam entre si na proporção sólidolíquido. Cada rota constituiu-se de duas etapas: a primeira de lixiviação ácida e a segunda de lixiviação ácida em meio oxidante. Todos ensaios foram realizados em sistema fechado e com agitação magnética constante, à pressão ambiente e com controle de temperatura, que foi de $95^{\circ} \mathrm{C}$. O detalhamento de cada rota encontra-se na Tabela 1:

Tabela 1. Detalhamento das rotas hidrometalúrgicas utilizadas no presente trabalho

\begin{tabular}{cccccc}
\hline Rota & $\begin{array}{c}\text { Relação } \\
\text { S/L }\end{array}$ & Etapa & Tipo de Ensaio & Duração & Temperatura \\
\hline A & $1: 10$ & 1 & $\begin{array}{c}\text { Lixiviação ácida } \\
\text { Lixiviação ácida em meio } \\
\text { oxidante }\end{array}$ & $\begin{array}{c}18 \mathrm{~h} \\
6 \mathrm{~h}\end{array}$ & \multirow{2}{*}{$95^{\circ} \mathrm{C}$} \\
\cline { 1 - 4 } B & $1: 20$ & 1 & $\begin{array}{c}\text { Lixiviação ácida } \\
\text { Lixiviação ácida em meio } \\
\text { oxidante }\end{array}$ & $\begin{array}{c}18 \mathrm{~h} \\
6 \mathrm{~h}\end{array}$ & \\
\hline
\end{tabular}




\subsubsection{Lixiviação Ácida}

A etapa 1 de ambas as rotas foi a de lixiviação ácida, utilizando ácido sulfúrico $2 \mathrm{M}$ como agente lixiviante. Utilizou-se a massa de $100 \mathrm{~g}$ de amostras quarteadas para as duas rotas, e o volume de ácido foi de 1000 e $2000 \mathrm{~mL}$ para as rotas A e B, respectivamente.

Ao final de cada etapa, o licor lixiviado passou por filtração simples em papel de filtro quantificado de filtragem rápida e porosidade $0,75 \mu \mathrm{m}$. Do licor resultante contendo os metais dissolvidos foi retirada uma alíquota de $10 \mathrm{~mL}$ para posterior análise química utilizando ICP-OES. A fração sólida retida no papel de filtro foi lavada com água deionizada e posta para secagem em estufa a $60^{\circ} \mathrm{C}$ por 24 horas. Após secagem o resíduo resultante foi pesado em balança analítica.

\subsubsection{Lixiviação ácida em meio oxidante}

A fração sólida resultante da etapa de lixiviação ácida foi submetida a uma etapa de lixiviação ácida em meio oxidante, nas condições supracitadas. O volume de ácido sulfúrico $2 \mathrm{M}$, a ser utilizado no ensaio foi calculado em função da massa de resíduo resultante da lixiviação anterior e da relação sólido-líquido pré-estabelecida para cada rota. Adicionalmente, foi inserido o volume de $15 \mathrm{~mL}$ peróxido de hidrogênio (130 volumes) no meio reacional a cada 15 minutos, até o final da lixiviação. Para a rota 1 , foi utilizado o volume de $740,4 \mathrm{~mL}$ de ácido sulfúrico para a massa de $74,04 \mathrm{~g}$ da fração sólida filtrada na etapa anterior, e para a rota 2 foi utilizado o volume de $1380 \mathrm{~mL}$ de ácido sulfúrico para a massa de $68,95 \mathrm{~g}$ da fração sólida filtrada na etapa anterior.

Ao final, o licor passou por filtração simples, da mesma forma que na etapa anterior. Da fração líquida foi retirada uma alíquota para ser encaminhada à análise química em ICP-OES, e o sólido foi seco em estufa a $60^{\circ} \mathrm{C}$ por 24 horas e pesado posteriormente.

\section{RESULTADOS E DISCUSSÃO}

\subsection{Processamento físico}

Após as etapas de cominuição e quarteamento, a perda de massa foi de $1,16 \%$ da massa total. Ao todo, foram utilizados $5 \mathrm{~kg}$ de placas mãe.

\subsection{Caracterização}

O resultado da caracterização dos materiais componentes da Placa Mãe encontrase na Figura 2 e é explicado nas seções abaixo.

\subsubsection{Digestão em água régia}

A partir da pesagem da fração sólida ao final da digestão, um balanço de massa foi realizado resultando em uma diferença de $35,5 \%$ da massa inicial. Isso representa a fração metálica da placa que foi lixiviada. A fração sólida representa $64,5 \%$ da 
massa total, a qual foi submetida ao ensaio de perda ao fogo para determinação das frações polimérica e cerâmica.

\subsubsection{Ensaio de perda ao fogo}

Da fração sólida, o balanço de massa feito na amostra antes e após o ensaio de perda ao fogo mostra uma perda de $40 \%$ da massa inicial, o que representa $25,8 \%$ da massa total da placa, sendo esta sua fração polimérica. O sólido restante, representando $60 \%$ da massa inicial e $38,7 \%$ da massa total da placa corresponde à fração de material cerâmico componente da placa. Tal resultado, somado com o obtido na digestão em água régia, corrobora a faixa descrita na literatura para composição de PCls $[2,7,8]$.

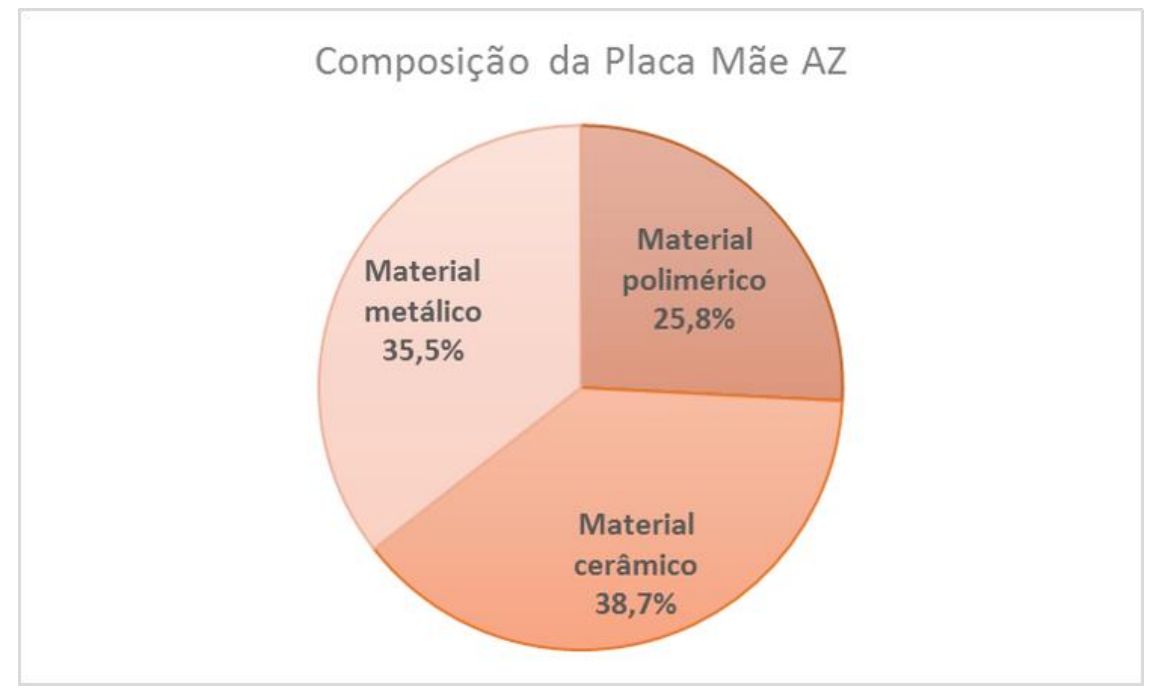

Figura 2. Composição percentual dos materiais componentes da Placa Mãe

\subsubsection{Análise Química}

Foram analisados os seguintes metais: $\mathrm{Ag}, \mathrm{Al}, \mathrm{Au}, \mathrm{Cu}, \mathrm{Fe}, \mathrm{Ni}, \mathrm{Sn}$ e $\mathrm{Zn}$. O resultado encontra-se na Figura 3: 


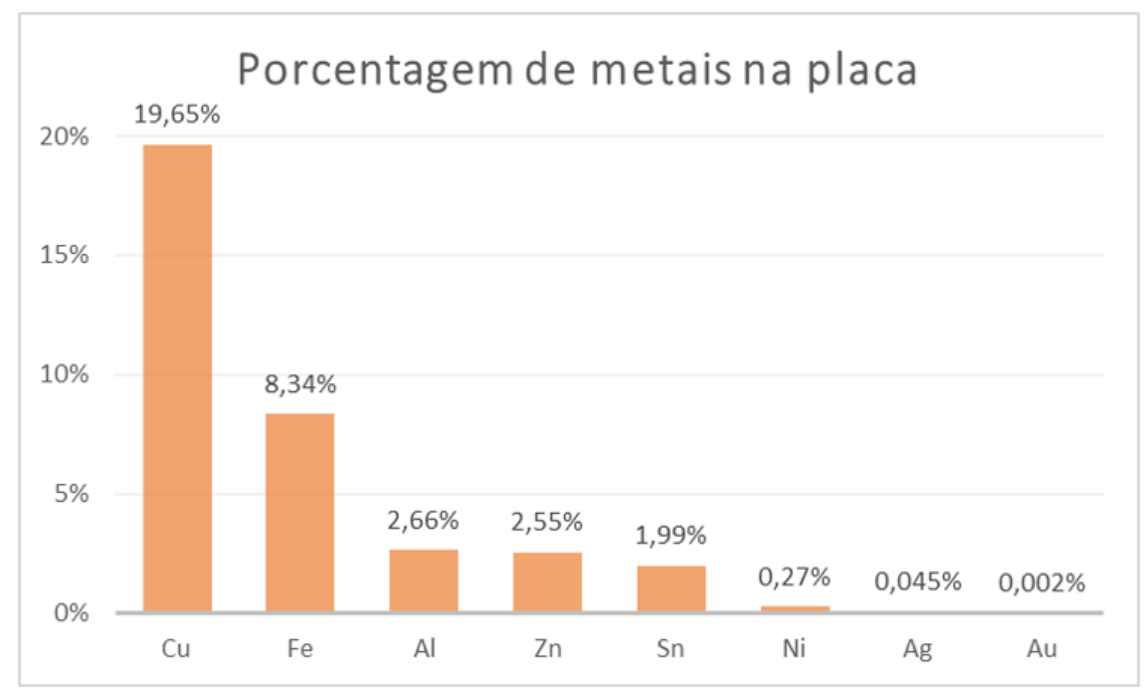

Figura 3. Porcentagem de composição dos metais na placa mãe considerando a massa total da placa

\subsection{Processamento Hidrometalúrgico}

Por meio da análise química do licor obtido ao final de cada etapa de lixiviação, foi possível quantificar a porcentagem de extração dos metais nas duas rotas. $O$ resultado se encontra nas Tabelas 2 e 3.

Tabela 2. Porcentagem de extração de metais em cada etapa de lixiviação e no total, para a Rota $A$

\begin{tabular}{cccc}
\hline & \multicolumn{3}{c}{ Porcentagem de Extração - Rota A } \\
\cline { 2 - 4 } Metal & $\begin{array}{c}\text { Lixiviação Ácida } \\
\text { Lixiviação Ácida em } \\
\text { meio oxidante }\end{array}$ & Total \\
\hline $\mathrm{Ag}$ & 0 & 37,1 & 37,1 \\
$\mathrm{Al}$ & 100 & 0 & 100 \\
$\mathrm{Au}$ & 0 & 0 & 0 \\
$\mathrm{Cu}$ & 0 & 54,1 & 54,1 \\
$\mathrm{Fe}$ & 100 & 0 & 100 \\
$\mathrm{Ni}$ & 33,3 & 45,4 & 78,7 \\
$\mathrm{Sn}$ & 76,1 & 1,9 & 78 \\
$\mathrm{Zn}$ & 13,8 & 85,6 & 99,4 \\
\hline
\end{tabular}

Tabela 3. Porcentagem de extração de metais em cada etapa de lixiviação e no total, para a Rota B

\begin{tabular}{cccc}
\hline & \multicolumn{3}{c}{ Porcentagem de Extração - Rota B } \\
\cline { 2 - 4 } Metal & $\begin{array}{c}\text { Lixiviação Ácida } \\
\text { Lixiviação Ácida em } \\
\text { Meio Oxidante }\end{array}$ & Total \\
\hline $\mathrm{Ag}$ & 0 & 100 & 100 \\
$\mathrm{Al}$ & 100 & 0 & 100 \\
$\mathrm{Au}$ & 0 & 0 & 0 \\
$\mathrm{Cu}$ & 0 & 100 & 100 \\
$\mathrm{Fe}$ & 100 & 0 & 100
\end{tabular}




\begin{tabular}{cccc}
$\mathrm{Ni}$ & 13,6 & 86,4 & 100 \\
$\mathrm{Sn}$ & 67,6 & 2,5 & 70,1 \\
$\mathrm{Zn}$ & 7,6 & 92,4 & 100 \\
\hline
\end{tabular}

\subsubsection{Lixiviação Ácida}

Pelos resultados apresentados acima, nota-se que as duas rotas tiveram comportamento equivalente em relação aos metais lixiviados e suas respectivas quantidades. Assim, Al e Fe foram lixiviados em sua totalidade nesta etapa nas rotas $A$ e B, o que é importante visto que a presença do Fe pode fazer com que ocorra um processo de cementação com $\circ \mathrm{Cu}$, atrapalhando sua lixiviação que, por conseguinte, prejudica a etapa seguinte [12].

Por outro lado, e como já era esperado, $\mathrm{Ag}, \mathrm{Au}$ e $\mathrm{Cu}$ não foram extraídos nesta etapa, sendo o $\mathrm{Cu}$ possível de ser lixiviado somente com ácido forte em meio oxidante, dadas suas características [13]. Como consequência disso, $\mathrm{Ni}$ e $\mathrm{Zn}$ também foram pouco lixiviados, uma vez que que ambos metais possuem a capacidade de formar ligas estáveis com o Cu [14-16]. Portanto, somente serão lixiviados quando o $\mathrm{Cu}$ também for. Sobre o Sn, tal metal forma compostos insolúveis com componentes da solução, como o sulfato de estanho, logo é esperado que sua lixiviação em toda rota hidrometalúrgica, seja ela qual for, não ocorra de forma representativa [17].

\subsubsection{Lixiviação Ácida em meio oxidante}

Uma vez que o $\mathrm{Fe}$ foi totalmente lixiviado na etapa anterior para as rotas $\mathrm{A}$ e $\mathrm{B}$, o $\mathrm{Cu}$ poderia ser lixiviado nesta etapa sem a interferência do processo de cementação. Porém, isto ocorreu somente na rota $\mathrm{B}$, onde houve $100 \%$ de lixiviação do $\mathrm{Cu}$, em detrimento dos $54,1 \%$ de lixiviação na rota $\mathrm{A}$. O Ni e o $\mathrm{Zn}$ também foram lixiviados, porém somente na rota $B$ isto ocorreu em sua totalidade para ambos metais, ao passo que na rota A foi alcançado 78,7 e $99,4 \%$ de lixiviação para o $\mathrm{Ni}$ e $\circ \mathrm{Zn}$, respectivamente. $\mathrm{Na}$ rota $\mathrm{A}$ ainda havia uma quantidade considerável de $\mathrm{Ni}$ não lixiviada. Isso talvez esteja associado ao fato de o $\mathrm{Cu}$ também não ter sido totalmente lixiviado nesta etapa, permanecendo o que foi explicado na seção anterior sobre a possibilidade de formação de ligas estáveis com o Níquel. Já no caso da Ag, esta foi totalmente lixiviada nesta etapa na rota $B$ em detrimento de uma lixiviação inexpressiva na rota $A$, de $37,1 \%$.

\section{CONCLUSÃO}

Os resultados indicam que, na rota $A$, a relação sólido-líquido de 1:10 permitiu que 0 processo se desse dentro do previsto de acordo com relatos da literatura, porém no tempo e condições estabelecidos não foi possível alcançar a totalidade da extração de todos os metais em duas etapas. Assim, seria necessária mais uma etapa de lixiviação, como por exemplo a lixiviação com ácido nítrico, para concluir o processo de lixiviação dos metais presentes na placa. Já na rota $B$, a quantidade de ácido estabelecida pela relação sólido-líquido de 1:20 possibilitou que todos os metais possíveis de serem lixiviados o fossem em duas etapas. Ag, $\mathrm{Al}, \mathrm{Cu}, \mathrm{Fe}, \mathrm{Ni}$ e $\mathrm{Zn}$ foram $100 \%$ lixiviados, o que evidencia que, neste estudo, esta é a melhor rota 
hidrometalúrgica para a recuperação de metais a partir de placas de circuito impresso, mais especificamente a placa mãe de computadores obsoletos.

\section{Agradecimentos}

Ao Conselho Nacional de Desenvolvimento Científico e Tecnológico (CNPq) pela concessão da bolsa de mestrado.

\section{REFERÊNCIAS}

1 Shokri A, Pahlevani F, Levick K, Cole I, Sahajwalla V. Synthesis of copper-tin nanoparticles from old computer printed circuit boards. J Clean Prod. 2017;142:258692.

2 Ghosh B, Ghosh MK, Parhi P, Mukherjee PS, Mishra BK. Waste Printed Circuit Boards recycling: An extensive assessment of current status. J Clean Prod. 2015;94:5-19.

3 Kumar V, Lee J chun, Jeong J, Jha MK, Kim B su, Singh R. Recycling of printed circuit boards (PCBs) to generate enriched rare metal concentrate. J Ind Eng Chem. 2015;21:805-13.

4 Zhan L, Xiang X, Xie B, Sun J. A novel method of preparing highly dispersed spherical lead nanoparticles from solders of waste printed circuit boards. Chem Eng J. 2016;303:261-7.

$5 \mathrm{Xu} \mathrm{Y,} \mathrm{Li} \mathrm{J,} \mathrm{LiliLiu.} \mathrm{Current} \mathrm{status} \mathrm{and} \mathrm{future} \mathrm{perspective} \mathrm{of} \mathrm{recycling} \mathrm{cooper} \mathrm{by}$ hidrometallurgy from waste printed circuit boards. Procedia Environ Sci. 2016;31:16270.

6 Diaz LA, Lister TE, Parkman JA, Clark GG. Comprehensive process for the recovery of value and critical materials from electronic waste. J Clean Prod. 2015;125:236-44.

7 Ilyas S, Ruan C, Bhatti HN, Ghauri MA, Anwar MA. Column bioleaching of metals from electronic scrap. Hydrometallurgy. 2010;101(3-4):135-40.

8 Kaya M. Recovery of metals and nonmetals from electronic waste by physical and chemical recycling processes. Waste Manag. 2016;57:64-90.

9 Official Journal of the European Union [página da internet] Directive 2002/96/EC of the European Parliament and of the Council on waste electrical and electronic equipment (WEEE). 2003 [acesso em 12 abr. 2017]. Disponível em: http://eur-lex.europa.eu/legalcontent/EN/TXT/?uri=celex\%3A32012L0019

10 Buzin PJWK, Heck NC, Tubino RMC. Recuperação dos metais e separação da liga de solda $\mathrm{Sn}-\mathrm{Pb}$ de resíduos de fabricação de placas de circuito impresso utilizando sistemas termodinâmicos autorreagentes. In: XXV Encontro Nacional de Tratamento de Minérios e de Metalurgia Extrativa \& VIII Meeting of the Southern Hemisphere on Mineral Technology. Goiânia - GO; 2013. p. 457-64.

11 Official Journal of the European Union [página da internet]. Directive 2002/95/EC of the European Parliament and of the Council of 27 January 2003 on the restriction of the use of certain hazardous substances in electrical and electronic equipment (RoHS). 2003 [acesso em 12 abr. 2017]. Disponível em: http://eur-lex.europa.eu/legalcontent/EN/TXT/?uri=CELEX:32002L0095.

12 Gros F, Baup S, Aurousseau M. Copper cementation on zinc and iron mixtures: Part 1: Results on rotating disc electrode. Hydrometallurgy. 2011;106(1-2):119-26.

13 Moraes VT De. Recuperação de Metais a Partir do Processamento Mecânico e Hidrometalúrgico de Placas de Circuito Impressos de Celulares Obsoletos [tese de doutorado]. São Paulo: Escola Politécnica da Universidade de São Paulo; 2011.

14 Ahmed IM, Nayl AA, Daoud JA. Leaching and recovery of zinc and copper from brass slag by sulfuric acid. J Saudi Chem Soc. 2016;20:S280-5.

15 Subramanian V, Chandramohan P, Srinivasan MP, Velmurugan S, Narasimhan S V. Corrosion of cupronickel alloy in permanganate under acidic condition. Corros Sci. 2007;49(2):620-36. 
16 Milošev I, Kosec T. Study of Cu-18Ni-20Zn Nickel Silver and other Cu-based alloys in artificial sweat and physiological solution. Electrochim Acta. 2007;52(24):6799-810.

17 Havlik T, Orac D, Petranikova M, Miskufova A. Hydrometallurgical treatment of used printed circuit boards after thermal treatment. Waste Manag. 2011;31(7):1542-6. 